\title{
Clinicopathological and prognostic significance of Ki-67, caspase-3 and p53 expression in gastric carcinomas
}

\author{
LI-JUN XIAO ${ }^{1,2}$, SHUANG ZHAO ${ }^{1,2}$, EN-HONG ZHAO ${ }^{3}$, XIN ZHENG $^{3}$, \\ WEN-FENG GOU ${ }^{1}$, YASUO TAKANO ${ }^{4}$ and HUA-CHUAN ZHENG ${ }^{1}$
}

\begin{abstract}
${ }^{1}$ Department of Biochemistry and Molecular Biology, College of Basic Medicine, Institute of Pathology and Pathophysiology, China Medical University, Shenyang, Liaoning; ${ }^{2}$ Department of Immunology, Chengde Medical College;

${ }^{3}$ Department of Surgical Oncology, The First Affiliated Hospital of Chengde Medical College, Chengde,

Hebei, P.R. China; ${ }^{4}$ Clinical Cancer Institute, Kanagawa Cancer Center, Yokohama, Kanagawa, Japan
\end{abstract}

Received March 8, 2013; Accepted July 23, 2013

DOI: $10.3892 / \mathrm{ol} .2013 .1532$

\begin{abstract}
The understanding of proliferative and apoptotic changes has aided the improvement of the diagnosis, treatment and prevention of gastric cancer. The present study aimed to investigate the clinicopathological and prognostic significance of Ki-67, caspase-3 and p53 in gastric cancer. The expression levels of Ki-67, caspase-3 and p53 were evaluated on tissue microarrays of gastric carcinomas specimens by immunohistochemistry and compared with the clinicopathological parameters and survival time of the patients. It was observed that the elder or male patients with gastric cancer showed p53 overexpression compared with the younger or female patients, respectively $(\mathrm{P}<0.05)$. The expression of $\mathrm{Ki}-67$ and $\mathrm{p} 53$ was positively associated with tumor-node-metastasis (TNM) staging $(\mathrm{P}<0.05)$. There was higher caspase- 3 and p53 expression in the intestinal-type compared with the diffuse-type of carcinomas $(\mathrm{P}<0.05)$. There was a positive correlation among Ki-67, caspase-3 and p53 expression in gastric cancer $(\mathrm{P}<0.05)$. A Kaplan-Meier analysis indicated that there was positive correlation between caspase-3 expression and the adverse prognosis of the patients $(\mathrm{P}>0.05)$. Cox's proportional hazards model indicated that the patient age, gender, depth of invasion, lymphatic invasion, lymph node metastasis, TNM staging, Lauren's classification and caspase-3 expression were independent prognostic factors for gastric carcinomas $(\mathrm{P}<0.05)$. The data indicated that the expression of $\mathrm{Ki}-67$, caspase- 3 and p53 may be involved in the progression or differentiation of gastric carcinoma. This
\end{abstract}

Correspondence to: Professor Hua-Chuan Zheng, Department of Biochemistry and Molecular Biology, College of Basic Medicine, Institute of Pathology and Pathophysiology, China Medical University, 92 North Second Avenue, Shenyang, Liaoning, P.R. China E-mail: zheng_huachuan@hotmail.com

Key words: gastric carcinoma, Ki-67, caspase-3, p53, clinicopathological significance, prognosis expression may be employed as an indicator of the pathobiological behavior and prognosis of gastric carcinomas.

\section{Introduction}

Despite a worldwide decline in incidence and mortality in the last 60 years, gastric cancer remains the fourth most common type of cancer and the second most frequent cause of cancer mortality. Gastric cancer continues to be a major health concern due to the slow decrease in incidence in Asia and the high mortality from diagnosed gastric carcinomas in the West, even though advanced diagnostic and operative techniques are widely applied in clinical practice $(1,2)$. Increased understanding of the proliferative and apoptotic changes in gastric cancer, particularly the identification of novel biomarkers for cancer diagnosis and targets for treatment, may result in the improvement of diagnosis, treatment and prevention.

Ki-67 antigen (also known as MKI67) is in the nuclei of cells in the $\mathrm{G}_{1}, \mathrm{~S}, \mathrm{G}_{2}$ and mitosis phases of the cell cycle and is associated with ribosomal RNA transcription. During interphase, Ki-67 antigen is exclusively detected within the cell nucleus, whereas in mitosis, the majority of the protein relocates to the surface of the chromosomes. Quiescent or resting cells in the $\mathrm{G}_{0}$-phase do not express the Ki-67 antigen (3), making the $\mathrm{Ki}-67$ antigen an excellent operational marker for determining the proliferation of a given cell population and the aggressiveness of malignancies (4). In experimental and clinical practice, Ki-67 and MIB-1 monoclonal antibodies are directed against different epitopes of the same proliferation-related antigen; whereas Ki-67 works only on frozen sections, MIB-1 may also be used on fixed sections (5).

The caspase-3 (CASP3) protein is a member of the cysteine-aspartic acid protease (caspase)/interleukin$1 \beta$-converting enzyme (ICE) family. CASP3 is activated directly by caspase- $8,-9$ and -10 in the apoptotic cell by extrinsic (death ligand) and intrinsic (mitochondrial) pathways to initiate apoptosis. CASP3 is synthesized as an inactive $32 \mathrm{kDa}$ proenzyme and processed during apoptosis into its active form, which is composed of two subunits, p17-20 and p10-12. Activated CASP3 is responsible for the cleavage of poly(ADP-ribose) polymerase (PARP), actin and sterol regula- 
tory element binding protein (SREBP), which are associated with apoptosis (6-8).

The p53 tumor suppressor gene is considered to be central in protecting against the development of cancer. The encoded protein is a master switch that coordinates and concentrates a plethora of stress signals, transforming them into a series of responses, including apoptosis or cell cycle arrest, in response to DNA damage, thereby maintaining genetic stability in the organism (9). Therefore, p53 has been described as 'the guardian of the genome' $(9,10)$. The p53 pathway is also involved in regulating metastasis-associated genes, including maspin, kai1, integrin, nm23, matrix metalloproteinase (MMP)-2, MMP-13 and the tissue inhibitor of metalloproteinase-3 (TIMP-3) (10-16). Although p53 inactivation in human cancer is a complex process that depends on the tissue type, p53 dysfunction may disorder the biological events of cancer cells, giving rise to their aggressive phenotypes.

Previously, we observed that p53 and Ki-67 were gradually increased from gastrointestinal mucosa to adenocarcinoma through adenoma. Accumulated p53 expression showed a positive association with the depth of invasion, local invasion via vessels and lymph node metastasis of gastrointestinal adenocarcinoma (GIA). Ki-67 expression was positively correlated with local invasion via vessels and negatively correlated with the dedifferentiation and liver metastasis of GIA (17). The present study investigated the clinicopathological and prognostic significance of Ki-67, CASP3 and p53 to clarify their roles in the regulation of the balance between proliferation and apoptosis.

\section{Materials and methods}

Patients. This retrospective study was performed on curatively-resected gastric carcinoma specimens collected in Toyama University Hospital (Toyama, Japan) between 1993 and 2006. The patients with gastric carcinomas consisted of 130 males and 301 females (age range, 38-88 years; mean age, 66.4 years). Archival materials were obtained from the Department of Pathology. In 165 cases, tumor development was accompanied by lymph node metastasis. None of the patients underwent chemotherapy, radiotherapy and adjuvant treatment prior to surgery. All patients were followed up by consulting their case documents and by telephone.

Pathology. All tissues were fixed in $10 \%$ neutralized formalin, embedded in paraffin and cut into $4-\mu \mathrm{m}$ sections stained with hematoxylin and eosin (HE) to confirm the histological diagnosis and microscopic characteristics. The staging for each gastric carcinoma was evaluated according to the Union Internationale le Contre Cancer (UICC) system, indicating the extent of tumor spread (17). The histological architecture was defined in terms of Lauren's classification $(18,19)$. Furthermore, the tumor size, depth of invasion, lymphatic and venous invasion and lymph node metastasis of the tumors were determined.

Tissue microarray (TMA). Representative areas of solid tumor were selected for sampling from HE-stained sections of the selected tumor cases, and 2-mm diameter tissue cores per donor block were punched out and transferred to a recipient block, with a maximum of 48 cores, using a Tissue Microarrayer (KIN-1; Azumaya, Tokyo, Japan). Sections (4- $\mu$ m thick) were consecutively cut from the microarrays and transferred to poly-lysine-coated glass slides. HE staining was performed for the confirmation of the tumor tissue.

Immunohistochemistry. Serial sections of TMA were deparaffinized with xylene, rehydrated with alcohol and subjected to immunohistochemical staining with intermittent microwave radiation, as previously described (20). Rabbit anti-human CASP3, rabbit anti-human Ki-67 (NovoCastra, Leica Biosystems Newcastle Ltd., Newcastle Upon Tyne, UK) and mouse anti-human p53 (Dako, Carpinteria, CA, USA) antibodies were used at 1:100 dilution to detect the respective proteins, with anti-rabbit or anti-mouse Envison-PO (Dako) as the secondary antibody. Binding was visualized with 3,3'-diaminobenzidine (DAB) and counterstaining with Mayer's hematoxylin was performed to aid orientation. Omission of the primary antibody was used as a negative control.

Immunoreactivity for $\mathrm{Ki}-67, \mathrm{p} 53$ and CASP3. In total, 100 cells from five representative fields of each section were randomly selected and counted in a blinded manner by two independent observers (L. Xiao and H.C. Zheng). Inconsistent data were discussed by the observers until final agreements were reached. The expression positivity was graded and counted as follows: 0 , negative; $1,1-50 \% ; 2,50-74 \%$; and $3, \geq 75 \%$. The staining intensity score was graded as follows: 1 , weak; 2 , intermediate; and 3, strong. The scores for Ki-67, CASP3 and p53 positivity and staining intensity were multiplied to obtain a final score, which determined their expression as follows:,$- 0 ;+, 1-2 ;++$, 3-4; and +++, 6-9.

Statistical analysis. The statistical evaluation was performed using Spearman's correlation test to analyze rank data. Kaplan-Meier survival plots were generated and comparisons between survival curves were made with the log-rank statistic. Cox's proportional hazards model was used for the multivariate analysis. SPSS 17.0 software (SPSS Inc., Chicago, IL, USA) was applied to analyze all data and $\mathrm{P}<0.05$ was considered to indicate a statistically significant difference.

\section{Results}

Ki-67 and p53 positivity was clearly localized in the nuclei of the gastric cancer cells, while CASP3 was detected in the cytoplasm of the cancer cells (Fig. 1). Ki-67 expression was positively correlated with tumor-node-metastasis (TNM) staging and p53 expression of gastric cancer $(\mathrm{P}<0.05)$, but not with the patients' age or gender, tumor size, depth of invasion, lymphatic or venous invasion, lymph node metastasis or Lauren's classification (P>0.05; Table I). CASP3 expression was positively correlated with Ki-67 expression in gastric carcinoma $(\mathrm{P}<0.05)$, but not with the patients' age or gender, tumor size, depth of invasion, lymphatic or venous invasion, lymph node metastasis or TNM staging $(\mathrm{P}>0.05)$. There was higher CASP3 expression in the intestinal-type compared with the diffuse-type of carcinoma $(\mathrm{P}<0.05)$. The elder or male patients with gastric cancer showed higher p53 expression compared with the younger or female patients, respectively $(\mathrm{P}<0.05$; Table II). p53 expression was 

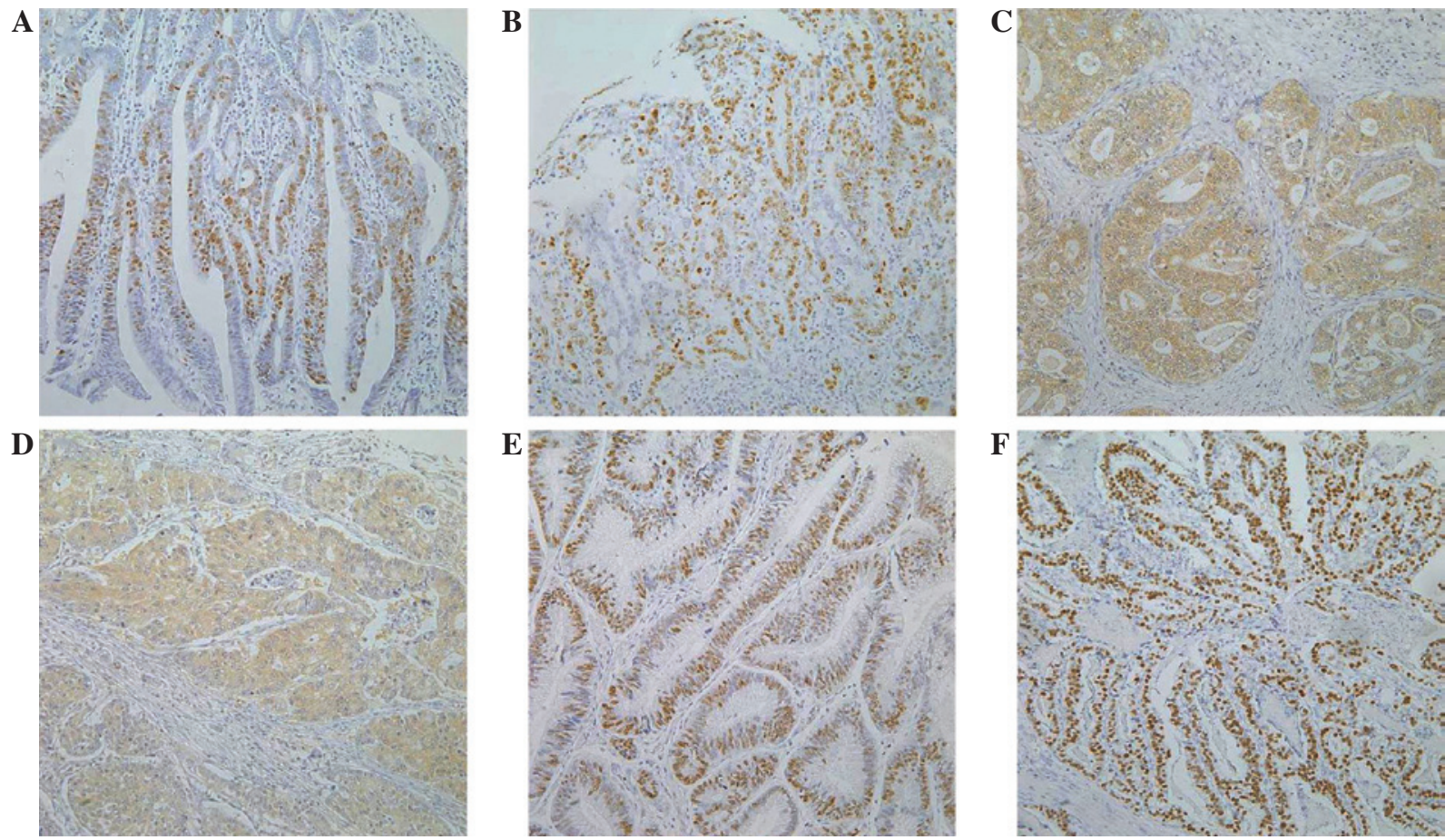

Figure 1. Expression of Ki-67, caspase-3 (CASP3) and p53 in gastric cancer. (A and B) Marked positivity for Ki-67 or (E and F) p53 is localized in the nucleus, while (C and D) CASP3 was observed in the cytoplasm of the gastric cancer cells.
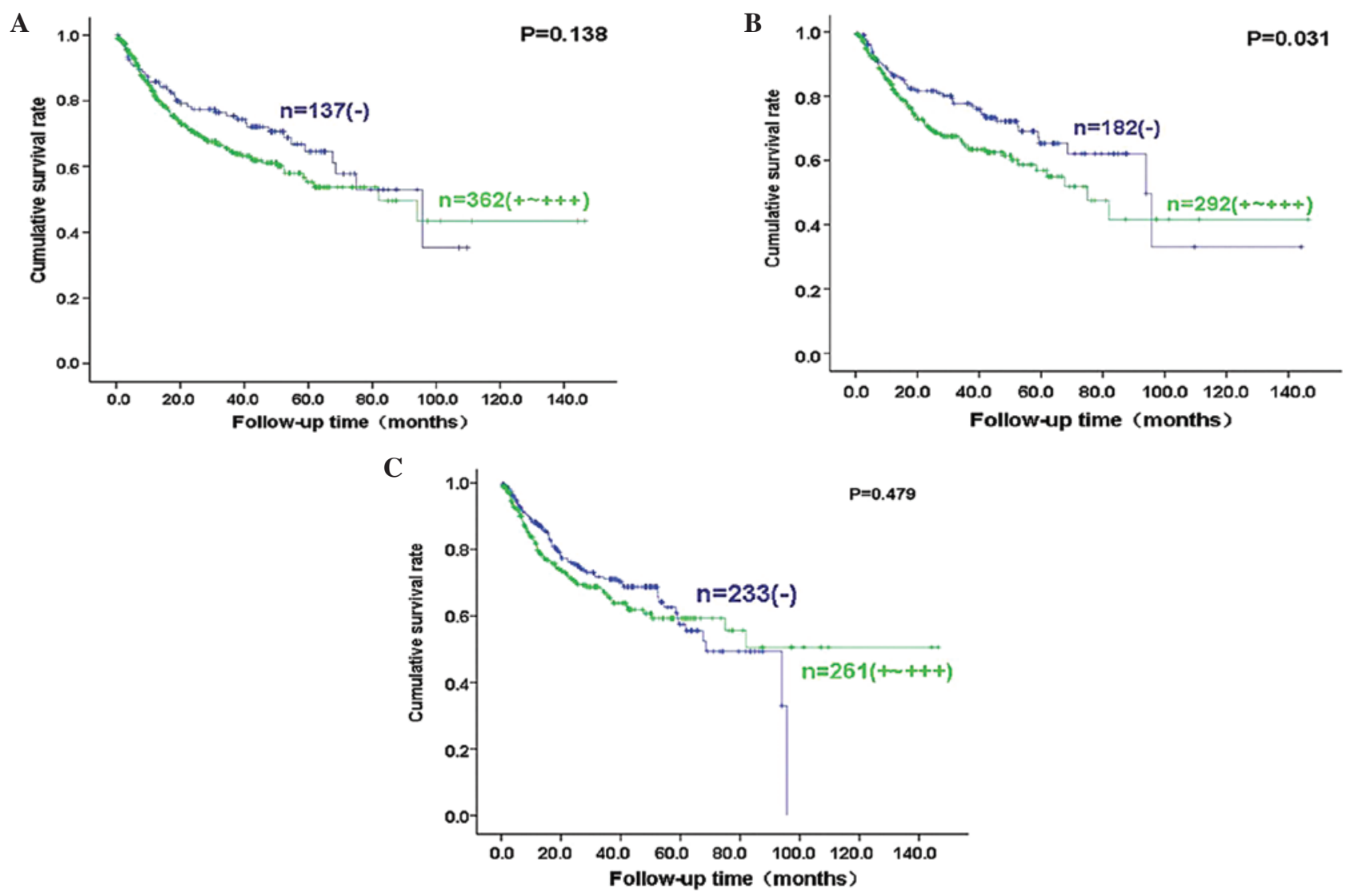

Figure 2. Prognostic significance of Ki-67, caspase-3 (CASP3) and p53 expression in the patients with gastric cancer. Kaplan-Meier curves for the cumulative survival rate of patients with gastric carcinomas according to (A) Ki-67, (B) CASP3 and (C) p53 expression status.

positively correlated with TNM staging and the CASP3 expression of gastric cancer $(\mathrm{P}<0.05)$, but not with the tumor size, depth of invasion, lymphatic or venous invasion, or lymph node metastasis $(\mathrm{P}>0.05)$. The intestinal-type carcinoma samples showed higher p53 expression compared with the diffuse-type samples $(\mathrm{P}<0.05$; Table III). 
Table I. Correlation between Ki-67 expression and clinicopathological features of gastric carcinomas.

\begin{tabular}{|c|c|c|c|c|c|c|c|}
\hline \multirow{2}{*}{$\begin{array}{l}\text { Clinicopathological } \\
\text { features }\end{array}$} & \multirow[b]{2}{*}{$\mathrm{n}$} & \multicolumn{4}{|c|}{ Ki-67 expression, $\mathrm{n}$} & \multirow[b]{2}{*}{$\mathrm{PR}, \%$} & \multirow[b]{2}{*}{ P-value } \\
\hline & & - & + & ++ & +++ & & \\
\hline Age, years & & & & & & & 0.062 \\
\hline$<65$ & 186 & 60 & 28 & 36 & 62 & 67.7 & \\
\hline$\geq 65$ & 245 & 55 & 29 & 57 & 104 & 77.6 & \\
\hline Gender & & & & & & & 0.539 \\
\hline Female & 130 & 38 & 14 & 26 & 52 & 70.8 & \\
\hline Male & 301 & 77 & 43 & 67 & 114 & 74.4 & \\
\hline Tumor size, $\mathrm{cm}$ & & & & & & & 0.146 \\
\hline$<4$ & 222 & 66 & 25 & 48 & 83 & 70.3 & \\
\hline$\geq 4$ & 209 & 49 & 32 & 45 & 83 & 76.6 & \\
\hline Depth of invasion & & & & & & & 0.380 \\
\hline $\mathrm{T}_{\mathrm{is}-1}$ & 220 & 57 & 28 & 48 & 87 & 74.1 & \\
\hline $\mathrm{T}_{2-4}$ & 211 & 58 & 29 & 45 & 79 & 72.5 & \\
\hline Lymphatic invasion & & & & & & & 0.534 \\
\hline- & 271 & 74 & 33 & 60 & 104 & 72.7 & \\
\hline+ & 159 & 41 & 24 & 33 & 61 & 74.2 & \\
\hline Venous invasion & & & & & & & 0.864 \\
\hline- & 373 & 99 & 52 & 86 & 136 & 73.5 & \\
\hline+ & 58 & 16 & 5 & 7 & 30 & 72.4 & \\
\hline Lymph node metastasis & & & & & & & 0.566 \\
\hline- & 262 & 72 & 32 & 62 & 96 & 72.5 & \\
\hline+ & 165 & 43 & 25 & 31 & 66 & 73.9 & \\
\hline TNM staging & & & & & & & 0.047 \\
\hline $0-\mathrm{I}$ & 247 & 59 & 32 & 58 & 98 & 76.1 & \\
\hline II-IV & 184 & 56 & 25 & 35 & 68 & 69.6 & \\
\hline Lauren's classification & & & & & & & 0.372 \\
\hline Intestinal-type & 214 & 50 & 32 & 46 & 86 & 76.6 & \\
\hline Diffuse-type & 203 & 62 & 23 & 46 & 72 & 69.5 & \\
\hline p53 expression & & & & & & & $<0.001$ \\
\hline- & 179 & 80 & 31 & 36 & 32 & 55.3 & \\
\hline+ & 37 & 6 & 9 & 8 & 14 & 83.8 & \\
\hline++ & 66 & 7 & 10 & 15 & 34 & 89.4 & \\
\hline+++ & 123 & 11 & 4 & 31 & 77 & 91.1 & \\
\hline
\end{tabular}

PR, positive rate; $\mathrm{T}_{\mathrm{is}}$, carcinoma in situ; $\mathrm{T}_{1}$, lamina propria and submucosa; $\mathrm{T}_{2}$, muscularis propria and subserosa; $\mathrm{T}_{3}$, exposure to serosa; $\mathrm{T}_{4}$, invasion into serosa; TNM, tumor-node-metastasis.

Follow-up information was available for 499 of the gastric carcinoma patients for periods ranging between 0.2 months and 12.2 years (mean, 70.1 months). Fig. 2 shows survival curves stratified according to Ki-67, CASP3 and p53 expression. Univariate analyses using the Kaplan-Meier method indicated that there was a higher cumulative survival rate among carcinoma cases with negative CASP3 expression compared with weak, moderate and strong CASP3 expression $(\mathrm{P}<0.05)$, whereas there was no correlation between Ki-67 or p53 expression and the survival rate of the patients with gastric cancer $(\mathrm{P}>0.05)$. Cox's proportional hazard model indicated that the patient age, gender, depth of invasion, lymphatic invasion, lymph node metastasis, TNM staging, Lauren's classification and CASP3 expression, but not the tumor size, venous invasion and $\mathrm{Ki}-67$ or p53 expression, were independent prognostic factors for gastric carcinomas $(\mathrm{P}<0.05$; Table IV).

\section{Discussion}

Cell proliferative activity is an important factor for assessing the biological behavior of carcinoma, and the identification of proliferating activities in tumors may be useful for predicting clinicopathological and prognostic significance. $\mathrm{Ki}-67$ is a nuclear non-histone protein, which is required for maintaining the cell cycle (22). Our previous study showed gradually increasing expression of $\mathrm{Ki}-67$ from the gastrointestinal mucosa to adenocarcinoma through adenoma (17). In the present study, it was observed that $\mathrm{Ki}-67$ was expressed in $30.4 \%$ of gastric cancers and that $\mathrm{Ki}-67$ expression was positively correlated with TNM staging and p53 expression, but not with aggressive parameters such as local invasion, lymph node metastasis and differentiation, which is consistent with previous studies (23-27). Xu et al (28) noted that the expression of Ki-67 antigen was significantly associated with distant metastases to 
Table II. Correlation between nuclear caspase-3 expression and clinicopathological features of gastric carcinomas.

\begin{tabular}{|c|c|c|c|c|c|c|c|}
\hline \multirow{2}{*}{$\begin{array}{l}\text { Clinicopathological } \\
\text { features }\end{array}$} & \multirow[b]{2}{*}{$\mathrm{n}$} & \multicolumn{4}{|c|}{ CASP3 expression, $n$} & \multirow[b]{2}{*}{$\mathrm{PR}, \%$} & \multirow[b]{2}{*}{ P-value } \\
\hline & & - & + & ++ & +++ & & \\
\hline Age, years & & & & & & & 0.100 \\
\hline$<65$ & 173 & 75 & 38 & 32 & 28 & 56.6 & \\
\hline$\geq 65$ & 232 & 81 & 56 & 42 & 53 & 65.1 & \\
\hline Gender & & & & & & & 0.412 \\
\hline Female & 125 & 54 & 24 & 22 & 25 & 56.8 & \\
\hline Male & 280 & 102 & 70 & 52 & 56 & 63.6 & \\
\hline Tumor size, $\mathrm{cm}$ & & & & & & & 0.255 \\
\hline$<4$ & 207 & 88 & 51 & 31 & 37 & 57.5 & \\
\hline$\geq 4$ & 198 & 68 & 43 & 43 & 44 & 65.7 & \\
\hline Depth of invasion & & & & & & & 0.141 \\
\hline $\mathrm{T}_{\mathrm{is}-1}$ & 205 & 88 & 42 & 31 & 44 & 57.1 & \\
\hline $\mathrm{T}_{2-4}$ & 200 & 68 & 52 & 43 & 37 & 66.0 & \\
\hline Lymphatic invasion & & & & & & & 0.447 \\
\hline- & 254 & 101 & 51 & 52 & 50 & 60.2 & \\
\hline+ & 150 & 55 & 42 & 22 & 31 & 63.3 & \\
\hline Venous invasion & & & & & & & 0.537 \\
\hline- & 347 & 132 & 81 & 67 & 67 & 62.0 & \\
\hline+ & 58 & 24 & 13 & 7 & 14 & 58.6 & \\
\hline Lymph node metastasis & & & & & & & 0.564 \\
\hline- & 246 & 100 & 55 & 40 & 51 & 59.3 & \\
\hline+ & 157 & 56 & 39 & 34 & 28 & 64.3 & \\
\hline TNM staging & & & & & & & 0.919 \\
\hline 0-I & 232 & 91 & 48 & 37 & 56 & 60.8 & \\
\hline II-IV & 173 & 65 & 46 & 37 & 25 & 62.4 & \\
\hline Lauren's classification & & & & & & & $<0.001$ \\
\hline Intestinal-type & 201 & 56 & 51 & 36 & 58 & 72.1 & \\
\hline Diffuse-type & 199 & 98 & 43 & 35 & 23 & 50.8 & \\
\hline Ki-67 expression & & & & & & & $<0.001$ \\
\hline- & 103 & 58 & 28 & 14 & 3 & 43.7 & \\
\hline+ & 52 & 28 & 8 & 9 & 7 & 46.2 & \\
\hline++ & 87 & 29 & 24 & 18 & 16 & 66.7 & \\
\hline+++ & 147 & 34 & 29 & 30 & 54 & 76.9 & \\
\hline
\end{tabular}

PR, positive rate; $\mathrm{T}_{\mathrm{is}}$, carcinoma in situ; $\mathrm{T}_{1}$, lamina propria and submucosa; $\mathrm{T}_{2}$, muscularis propria and subserosa; $\mathrm{T}_{3}$, exposure to serosa; $\mathrm{T}_{4}$, invasion into serosa; TNM, tumor-node-metastasis; CASP3, caspase-3.

the liver, ovary and adrenal gland, but not to the histological type, growth pattern, depth of invasion, histological differentiation or the metastases to local lymph nodes. Several studies have reported that $\mathrm{Ki}-67$ expression was a more valuable independent prognostic predictor for the survival of patients with gastric cancer $(24,27,29)$, which is contrary to the present data.

Normal cells contain only a small amount of caspases in the form of inactive zymogens, and activated caspases have been transformed to proteases via the catalytic activity of enzymes capable of cleaving a number of substrate proteins, resulting in apoptosis. CASP3 is activated by a series of cascade reactions, until eventually DNase (CAD, CPAN or DEF40) is activated, which belongs to the $\mathrm{Mg}^{2+}$-dependent endonucleases, and acts as a killer in apoptosis $(6,31)$. Reportedly, CASP3 expression is higher in normal tissues compared with gastric carcinoma tissue (6,32). Hoshi et al (32) also observed that the positive rate of CASP3 expression was lower in gastric cancers compared with their adjacent mucosa and gastric adenoma. In the present study, there was higher CASP3 expression in intestinal-type compared with diffuse-type carcinoma, indicating that its aberrant expression underlies the molecular mechanisms of the differentiation of gastric cancer. Additionally, CASP3 was also demonstrated to correlate with the poor prognosis of patients with gastric cancer as an independent factor, in agreement with the study by Isobe et al (33). The lack of correlation between CASP3 and aggressive behaviors of gastric cancer was consistent with our previous findings (6). Notably, the positive association between CASP3 and Ki-67 expression suggested the hypothesis that highly proliferating carcinomas may have a high apoptotic potential, contrary to results observed in a previous study (32).

The p53 gene is a tumor suppressor gene located on chromosome 17p13.1 and the single most common target for genetic alterations in human cancer, which is activated in 
Table III. Relationship between p53 expression and clinicopathological features of gastric carcinomas.

\begin{tabular}{|c|c|c|c|c|c|c|c|}
\hline \multirow{2}{*}{$\begin{array}{l}\text { Clinicopathological } \\
\text { features }\end{array}$} & \multirow[b]{2}{*}{$\mathrm{n}$} & \multicolumn{4}{|c|}{ p53 expression, $\mathrm{n}$} & \multirow[b]{2}{*}{$\mathrm{PR}, \%$} & \multirow[b]{2}{*}{ P-value } \\
\hline & & - & + & ++ & +++ & & \\
\hline Age, years & & & & & & & 0.032 \\
\hline$<65$ & 175 & 90 & 16 & 29 & 40 & 48.6 & \\
\hline$\geq 65$ & 247 & 99 & 22 & 38 & 88 & 59.9 & \\
\hline Gender & & & & & & & 0.027 \\
\hline Female & 127 & 65 & 12 & 20 & 30 & 48.8 & \\
\hline Male & 295 & 124 & 26 & 47 & 98 & 58.0 & \\
\hline Tumor size, $\mathrm{cm}$ & & & & & & & 0.697 \\
\hline$<4$ & 214 & 95 & 20 & 35 & 64 & 55.6 & \\
\hline$\geq 4$ & 208 & 94 & 18 & 32 & 64 & 54.8 & \\
\hline Depth of invasion & & & & & & & 0.169 \\
\hline $\mathrm{T}_{\mathrm{is}-1}$ & 215 & 89 & 20 & 39 & 67 & 58.6 & \\
\hline $\mathrm{T}_{2-4}$ & 207 & 100 & 18 & 28 & 61 & 51.7 & \\
\hline Lymphatic invasion & & & & & & & 0.861 \\
\hline- & 264 & 119 & 22 & 46 & 77 & 54.9 & \\
\hline+ & 157 & 70 & 16 & 20 & 51 & 55.4 & \\
\hline Venous invasion & & & & & & & 0.721 \\
\hline- & 362 & 160 & 34 & 61 & 107 & 55.8 & \\
\hline+ & 60 & 29 & 4 & 6 & 21 & 51.7 & \\
\hline Lymph node metastasis & & & & & & & 0.532 \\
\hline- & 253 & 113 & 21 & 45 & 74 & 55.3 & \\
\hline+ & 164 & 76 & 16 & 21 & 51 & 53.7 & \\
\hline TNM staging & & & & & & & 0.047 \\
\hline $0-\mathrm{I}$ & 241 & 98 & 22 & 43 & 78 & 59.3 & \\
\hline II-IV & 181 & 91 & 16 & 24 & 50 & 49.7 & \\
\hline Lauren's classification & & & & & & & $<0.001$ \\
\hline Intestinal-type & 212 & 66 & 22 & 42 & 82 & 68.9 & \\
\hline Diffuse-type & 200 & 119 & 13 & 24 & 44 & 40.5 & \\
\hline CASP3 expression & & & & & & & 0.004 \\
\hline- & 142 & 95 & 11 & 12 & 24 & 33.1 & \\
\hline+ & 90 & 42 & 4 & 18 & 26 & 53.3 & \\
\hline++ & 72 & 25 & 8 & 13 & 26 & 65.3 & \\
\hline+++ & 81 & 12 & 9 & 18 & 42 & 85.2 & \\
\hline
\end{tabular}

PR, positive rate; $T_{i s}$, carcinoma in situ; $T_{1}$, lamina propria and submucosa; $T_{2}$, muscularis propria and subserosa; $T_{3}$, exposure to serosa; $T_{4}$, invasion into serosa; TNM, tumor-node-metastasis; CASP3, caspase-3.

Table IV. Multivariate analysis of clinicopathological variables for the survival of the patients with gatric carcinomas.

\begin{tabular}{lrr}
\hline Clinicopathological parameters & Relative risk $(95 \%$ CI) & P-value \\
\hline Age $(\geq 65$ years) & $1.962(1.342-2.870)$ & 0.001 \\
Gender (female) & $1.679(1.079-2.612)$ & 0.022 \\
Tumor size $(>4 \mathrm{~cm})$ & $1.511(0.890-2.566)$ & 0.126 \\
Depth of invasion $\left(\mathrm{T}_{2-4}\right)$ & $5.255(2.376-11.622)$ & $<0.001$ \\
Lymphatic invasion (+) & $2.193(1.421-3.383)$ & $<0.001$ \\
Venous invasion $(+)$ & $1.158(0.756-1.774)$ & 0.500 \\
Lymph node metastasis $(+)$ & $3.629(1.848-7.126)$ & $<0.001$ \\
TNM staging (III-IV) & $0.309(0.138-0.694)$ & 0.004 \\
Lauren's classification & $2.251(1.457-3.477)$ & $<0.001$ \\
Ki-67 expression $(+$ to +++$)$ & $0.982(0.822-1.172)$ & 0.837 \\
CASP3 expression $(+$ to +++$)$ & $1.277(1.064-1.533)$ & 0.009 \\
p53 expression $(+$ to +++$)$ & $1.112(0.947-1.306)$ & 0.194 \\
\hline
\end{tabular}

CI, confidence interval; TNM, tumor-node-metastasis; CASP3, caspase-3. 
response to genotoxic and non-genotoxic insults to cells (34) Mutated p53 lacks the DNA repair regulation of the cell cycle and results in metabolically stable abnormal protein that accumulates in the nucleus, which may be detected by immunohistochemistry (35). Our previous studies showed that aberrant p53 overexpression was more common in gastric carcinoma than adenoma (17) or intestinal metaplasia (36). In the present study, it was shown that p53 expression was positively correlated with the TNM staging and CASP3 expression of gastric cancer, and that expression was higher in intestinal-type compared with diffuse-type carcinomas, indicating that p53 expression may be involved in the progression and differentiation of gastric cancer. Gonçalves et al (35) also noted that p53 expression was more frequent among gastric intestinal-type, differentiated and macroscopically elevated cancers. Significantly shorter survival times were observed in p53-negative patients compared with p53-positive patients. Tzanakis et al (37) demonstrated that a more marked expression of p53 was associated with a tumor size of $>5 \mathrm{~cm}$, and that advanced stage p53 expression was significantly decreased in poorly-differentiated adenocarcinoma compared with well- or moderately-differentiated adenocarcinoma, which is consistent with the present results. Unlike the present survival data, p53 overexpression was an independent adverse prognostic factor for survival (37).

In summary, the expression of Ki-67, CASP3 and p53 may be involved in the progression or differentiation of gastric carcinoma. These expression levels may be utilized as indicators of the pathobiological behaviors or prognosis of gastric carcinomas.

\section{Acknowledgements}

This study was supported by the Shenyang Science and Technology Grant (F11-264-1-10 and F12-277-1-01), Liaoning Science and Technology Grants from the Natural Scientific Foundation of China (81101885, 81101886 and 81172371) and a Grant-in-aid for Scientific Research from the Ministry of Education, Culture, Sports and Technology of Japan (23659958).

\section{References}

1. Rivera F, Vega-Villegas ME and López-Brea MF: Chemotherapy of advanced gastric cancer. Cancer Treat Rev 33: 315-324, 2007.

2. Kelley JR and Duggan JM: Gastric cancer epidemiology and risk factors. J Clin Epidemiol 56: 1-9, 2003.

3. Scholzen T and Gerdes J: The Ki-67 protein: from the known and the unknown. J Cell Physiol 182: 311-322, 2000.

4. Endl E and Gerdes J: The Ki-67 protein: fascinating forms and an unknown function. Exp Cell Res 257: 231-237, 2000.

5. Chino O, Osamura Y, Kise Y, Nishi T, Shimada H, Tanaka M, Kijima $\mathrm{H}$ and Makuuchi $\mathrm{H}$ : Acceleration of the proliferative activity of esophageal carcinoma with invasion beyond the muscularis mucosae; immunohistochemical analysis using MIB-1 for the Ki-67 antigen. Tokai J Exp Clin Med 32: 115-120, 2007.

6. Zheng HC, Sun JM, Wei ZL, Yang XF, Zhang YC and Xin Y: Expression of Fas ligand and caspase-3 contributes to formation of immune escape in gastric cancer. World J Gastroenterol 9: 1415-1420, 2003.

7. Kumar S: The apoptotic cysteine protease CPP32. Int J Biochem Cell Biol 29: 393-396, 1997.

8. Sternberg MJ, Bates PA, Kelley LA and MacCallum RM: Progress in protein structure prediction: assessment of CASP3. Curr Opin Struct Biol 9: 368-373, 1999.
9. Soussi T: The p53 pathway and human cancer. Br J Surg 92: 1331-1332, 2005.

10. Marreiros A, Dudgeon K, Dao V, Grimm MO, Czolij R, Crossley M and Jackson P: KAI1 promoter activity is dependent on p53, junB and AP2: evidence for a possible mechanism underlying loss of KAI1 expression in cancer cells. Oncogene 24: 637-649, 2005.

11. Ito R, Nakayama H, Yoshida K, Oda N and Yasui W: Loss of maspin expression is associated with development and progression of gastric carcinoma with p53 abnormality. Oncol Rep 12: 985-990, 2004.

12. Ala-aho R, Grénman R, Seth P and Kähäri VM: Adenoviral delivery of p53 gene suppresses expression of collagenase-3 (MMP-13) in squamous carcinoma cells. Oncogene 21: $1187-1195,2002$.

13. Yan C, Wang H and Boyd DD: ATF3 represses 72-kDa type IV collagenase (MMP-2) expression by antagonizing p53-dependent transactivation of the collagenase promoter. J Biol Chem 277: 10804-10812, 2002.

14. Loging WT and Reisman D: Inhibition of the putative tumor suppressor gene TIMP-3 by tumor-derived p53 mutants and wild type p53. Oncogene 18: 7608-7615, 1999.

15. Chen SL, Wu YS, Shieh HY, Yen CC, Shen JJ and Lin KH: P53 is a regulator of the metastasis suppressor gene Nm23-H1. Mol Carcinog 36: 204-214, 2003.

16. de la Fuente MT, Casanova B, Cantero E, Hernández del Cerro M, Garcia-Marco J, Silva A and Garcia-Pardo A: Involvement of p53 in alpha4betal integrin-mediated resistance of B-CLL cells to fludarabine. Biochem Biophys Res Commun 311: 708-712, 2003.

17. Zheng H, Tsuneyama K, Cheng C, Takahashi H, Cui Z, Murai Y, Nomoto K and Takano Y: An immunohistochemical study of P53 and Ki-67 in gastrointestinal adenoma and adenocarcinoma using tissue microarray. Anticancer Res 26: 2353-2360, 2006

18. Sobin LH and Wittekind CH (eds): TNM Classification of Malignant Tumors. 6th edition. John Wiley and Sons, Hoboken, NJ, 2002.

19. Zheng H, Takahashi H, Murai Y, Cui Z, Nomoto K, Miwa S, Tsuneyama $\mathrm{K}$ and Takano Y: Pathobiological characteristics of intestinal and diffuse-type gastric carcinoma in Japan: an immunostaining study on the tissue microarray. J Clin Pathol 60: 273-277, 2007.

20. Zheng HC, Li XH, Hara T, Masuda S, Yang XH, Guan YF and Takano Y: Mixed-type gastric carcinomas exhibit more aggressive features and indicate the histogenesis of carcinomas. Virchows Arch 452: 525-534, 2008.

21. Kumada T, Tsuneyama K, Hatta H, Ishizawa S and Takano Y: Improved 1-h rapid immunostaining method using intermittent microwave irradiation: practicability based on 5 years application in Toyama Medical and Pharmaceutical University Hospital. Mod Pathol 17: 1141-1149, 2004.

22. Czyzewska J, Guzińska-Ustymowicz K, Pryczynicz A, Kemona $\mathrm{A}$ and Bandurski R: Immunohistochemical evaluation of Ki-67, PCNA and MCM2 proteins proliferation index (PI) in advanced gastric cancer. Folia Histochem Cytobiol 47: 289-296, 2009.

23. Lazăr D, Tăban S, Sporea I, Dema A, Cornianu M, Lazăr E, Goldiş A and Vernic C: Ki-67 expression in gastric cancer. Results from a prospective study with long-term follow-up. Rom J Morphol Embryol 51: 655-661, 2010.

24. Lee HE, Kim MA, Lee BL and Kim WH: Low Ki-67 proliferation index is an indicator of poor prognosis in gastric cancer. J Surg Oncol 102: 201-206, 2010.

25. Joo YE, Chung IJ, Park YK, Koh YS, Lee JH, Park CH, Lee WS, Kim HS, Choi SK, Rew JS, Park CS and Kim SJ: Expression of cyclooxygenase-2, p53 and Ki-67 in gastric cancer. J Korean Med Sci 21: 871-876, 2006

26. Oshima CT, Iriya $\mathrm{K}$ and Forones NM: Ki-67 as a prognostic marker in colorectal cancer but not in gastric cancer. Neoplasma 52: 420-424, 2005.

27. Kikuyama S, Kubota T, Shimizu K and Miyakita M: Ki-67 antigen expression in relation to clinicopathological variables and prognosis in gastric cancer. Oncol Rep 5: 867-870, 1998.

28. Xu L, Zhang SM, Wang YP, Zhao FK, Wu DY and Yan X: Relationship between DNA ploidy, expression of Ki-67 antigen and gastric cancer metastasis. World J Gastroenterol 5: 10-11, 1999.

29. He WL, Li YH, Yang DJ, Song W, Chen XL, Liu FK, Wang Z, Li W, Chen W, Chen CY, He YL and Zhan WH: Combined evaluation of centromere protein $\mathrm{H}$ and $\mathrm{Ki}-67$ as prognostic biomarker for patients with gastric carcinoma. Eur J Surg Oncol 39: 141-149, 2013 
30. Stepień A, Izdebska M and Grzanka A: The types of cell death. Postepy Hig Med Dosw (Online) 61: 420-428, 2007 (In Polish).

31. Li YH, Wang C, Meng K, Chen LB and Zhou XJ: Influence of survivin and caspase- 3 on cell apoptosis and prognosis in gastric carcinoma. World J Gastroenterol 10: 1984-1988, 2004.

32. Hoshi T, Sasano H, Kato K, Yabuki N, Ohara S, Konno R, Asaki S, Toyota T, Tateno $\mathrm{H}$ and Nagura $\mathrm{H}$ : Immunohistochemistry of Caspase3/CPP32 in human stomach and its correlation with cell proliferation and apoptosis. Anticancer Res 18: 4347-4353, 1998.

33. Isobe N, Onodera H, Mori A, Shimada Y, Yang W, Yasuda S, Fujimoto A, Ooe H, Arii S, Kitaichi $M$ and Imamura $M$ : Caspase-3 expression in human gastric carcinoma and its clinical significance. Oncology 66: 201-209, 2004.
34. Steele RJ and Lane DP: P53 in cancer: a paradigm for modern management of cancer. Surgeon 3: 197-205, 2005.

35. Goncalves AR, Carneiro AJ, Martins I, de Faria PA, Ferreira MA, de Mello EL, Fogaça HS, Elia CC and de Souza HS: Prognostic significance of p53 protein expression in early gastric cancer. Pathol Oncol Res 17: 349-355, 2011.

36. Wang L, Zhang XY, Xu L, Liu WJ, Zhang J and Zhang JP: Expression and significance of $\mathrm{p} 53$ and $\mathrm{mdm} 2$ in atypical intestinal metaplasia and gastric carcinoma. Oncol Lett 2: 707-712, 2011.

37. Tzanakis NE, Peros G, Karakitsos P, Giannopoulos GA, Efstathiou SP, Rallis G, Tsigris C, Kostakis A and Nikiteas NI: Prognostic significance of p53 and Ki67 proteins expression in Greek gastric cancer patients. Acta Chir Belg 109: 606-611, 2009. 